\title{
ANALISIS TINGKAT KESEHATAN BANK BERDASARKAN CAMEL PADA BPR LESTARI
}

\author{
Oleh : R. Agrosamdhyo, Putu Linda Sari \\ ( ragrosamdhyo@gmail.com)
}

\begin{abstract}
ABSTRAK
Tingkat kesehatan keuangan bank adalah hasil penilaian kualitatif atas berbagai aspek yang berpengaruh terhadap kondisi atau kinerja suatu bank melalui Penilaian Kuantitatif dan atau Penilaian Kualitatif terhadap faktor-faktor CAMEL.

Penelitian ini bertujuan untuk mengetahui kondisi tingkat kesehatan keuangan bank pada BPR Lestari periode Maret 2017-2018.

Subjek penelitian ini adalah bagian Financial Management. Objek penelitian ini adalah Neraca, Laporan Laba/Rugi, Laporan Komitmen dan Kontijensi dan Informasi Lainnya periode Maret 2017-2018. Jenis penelitian ini adalah penelitian deskriptif dengan data yang digunakan laporan keuangan. Teknik pengumpulan data adalah wawancara dan observasi. Analisis data yang digunakan adalah analisis Capital, Asset Quality, Management, Earning, dan Liquidity (CAMEL) yang digunakan untuk menilai tingkat kesehatan keuangan bank.

Hasil penelitian ini menunjukkan bahwa, tingkat kesehatan keuangan bank dilihat dari faktor permodalan periode maret 2017-2018 masing-masing 14,30\% dan 14,38\%. Rasio ini termasuk dalam kategori sehat. Rasio aktiva produktif masing-masing sebesar $2 \%$ dan $1 \%$. Rasio ini termasuk dalam kategori sehat. Faktor rentabilitas berdasarkan Return On Asset (ROA) masingmasing sebesar $4,72 \%$ dan 4,54\% yang termasuk kategori sehat. Faktor rentabilitas berdasarkan Biaya Operasional Pendapatan Operasional (BOPO) masing-masing sebesar 70,58\% dan 69,01\% nilai ini termasuk dalam kategori cukup sehat. Faktor likuiditas berdasarkan Cash Ratio (CR) masing-masing sebesar 3,65\% dan 11,90\% hasil rasio ini termasuk dalam kategori cukup sehat menjadi sehst, sedangkan Loan Deposit Ratio (LDR) masing-masing sebesar 70,23\% dan $70,12 \%$ yang termasuk pada kategori sehat.
\end{abstract}

Kata kunci: Analisis, Tingkat Kesehatan Bank, CAMEL

\section{A. PENDAHULUAN}

Kesehatan atau kondisi keuangan bank dan non keuangan bank merupakan kepentingan semua pihak terkait, baik pemilik, pengelola (manajemen) bank, masyarakat pengguna jasa bank, Bank Indonesia selaku otoritas pengawasan bank, dan pihak lainnya. Kondisi keuangan bank tersebut dapat digunakan oleh pihak-pihak tersebut untuk mengevaluasi kinerja bank dalam menerapkan prinsip kehati-hatian, kepatuhan terhadap ketentuan yang berlaku dan manajemen risiko.

Tingkat kesehatan keuangan bank adalah hasil penilaian kualitatif atas berbagai aspek yang berpengaruh terhadap kondisi atau kinerja suatu bank melalui Penilaian Kuantitatif dan atau Penilaian Kualitatif terhadap faktor-faktor Capital, Asset Quality, Management, Earning, dan Liquidity yang disingkat CAMEL. Perkembangan industri perbankan, terutama produk dan jasa yang semakin kompleks dan beragam akan meningkatkan eksposur risiko yang dihadapi bank. Perubahan eksposur risiko bank dan penerapan manajemen risiko akan memengaruhi profil 
risiko bank yang selanjutnya berakibat pada kondisi bank secara keseluruhan. Perkembangan metodologi penilaian kondisi keuangan bank-bank senantiasa bersifat dinamis sehingga sistem penilaian tingkat kesehatan keuangan bank harus diatur kembali agar lebih mencerminkan kondisi bank saat ini dan di waktu yang akan datang.

\section{Perumusan Masalah}

Dari latar belakang tersebut maka penulis tertarik untuk memilih dan menulis mengenai tingkat kesehatan keuangan bank Bank Perkreditan Rakyat. Untuk itu, penulis mengambil judul "ANALIS TINGKAT KESEHATAN BANK BERDASARKAN CAMEL PADA BPR LESTARI".

\section{B. LANDASAN TEORI}

\section{Pengertian Bank}

Bank secara sederhana dapat diartikan sebagai lembaga keuangan yang kegiatan utamanya adalah menghimpun dana dari masyarakat dan menyalurkan kembali dana tersebut ke masyarakat serta memberikan jasa Bank lainnya. Jika di tinjau dari asal mula terjadinya bank, maka pengertian bank adalah meja atau tempat untuk menukarkan uang.

\section{Pengertian dan Tujuan Laporan Keuangan}

Dengan demikian disamping menggambarkan kondisi keuangan suatu bank laporan keuangan juga dapat menilai kinerja manajemen bank yang bersangkutan. Penilaian kinerja manajemen akan menjadi dasar apakah manajemen berhasil atau tidak dalam melaksanakan kebijakan yang telah digariskan dalam bidang manajemen keuangan khususnya dan hal ini akan dapat tergambar dari laporan keuangan yang disusun oleh pihak manajemen.

\section{Kesehatan Keuangan Bank}

Kesehatan keuangan bank adalah kemampuan suatu bank untuk melakukan kegiatan operasional perbankan secara normal dan mampu memenuhi semua kewajibannya dengan baik dengan caracara yang sesuai dengan peraturan perbankan yang berlaku. Menyadari arti pentingnya kesehatan suatu bank bagi pembentukan kepercayaan dalam dunia perbankan serta untuk melaksanakan prinsip kehati-hatian dalam dunia perbankan, maka Bank Indonesia menerapkan aturan tentang kesehatan bank. Diharapkan bank dalam kondisi sehat semua, sehingga idak akan merugikan masyarakat yang berhubungan dengan perbankan.

Penilaian tingkat kesehatan bank dapat diukur dengan menggunakan analisis CAMEL. Penilaian tingkat kesehatan keuangan bank penting artinya bagi pembentukan kepercayaan dalam dunia perbankan serta untuk melaksanakan prinsip kehati-hatian atau prudential banking dalam dunia perbankan. Dengan penilaian tingkat kesehatan keuangan bank, diharapkan bank selalu dalam kondisi yang sehat sehingga tidak melakukan kegiatan yang merugikan masyarakat yang berhubungan dengan dunia perbankan. Penilaian tingkat kesehatan bank dapat diukur dengan menggunakan analisis CAMEL. Kriteria terhadap penilaian dalam kesehatan keuangan bank ditetapkan dalam.". 


\section{METODE PENELITIAN}

Penelitian ini dilakukan Adapun penelitian yang dilakukan oleh penulis mengambil data dari laporan keuangan dan dioalh menggunakan rasio keuangan. Teknik ini dilaksanakan karena beberapa pertimbangan yaitu karena alasan keterbatasan waktu, tenaga, dan dana.

\section{PEMBAHASAN}

\section{1.) Analisis Faktor Permodalan}

Perhitungan Rasio CAR tahun 2017:

$$
\begin{gathered}
\text { Rasio CAR } \quad: \frac{404,433.086}{2,826,503.756} \times 100 \% \\
: 14,30 \%
\end{gathered}
$$

Perhitungan Rasio CAR tahun 2018:

$$
\begin{gathered}
\text { Rasio CAR } \quad \frac{467.836 .719}{3.252 .268 .111} \times 100 \% \\
: 14,38 \%
\end{gathered}
$$

Tabel 4.9

Perhitungan Rasio CAR

\begin{tabular}{|l|l|c|c|}
\hline \multirow{2}{*}{ No } & \multirow{2}{*}{ Uraian } & \multicolumn{2}{c|}{ Tahun } \\
\cline { 3 - 4 } & & $\mathbf{2 0 1 7}(\boldsymbol{\%})$ & $\mathbf{2 0 1 8}(\boldsymbol{\%})$ \\
\hline 1 & CAR & 14,30 & 14,38 \\
\hline 2 & ATMR & 2.826 .503 .756 & 3.252 .268 .111 \\
\hline 3 & Kriteria & SEHAT & SEHAT \\
\hline
\end{tabular}

Sumber: Data diolah, perhitungan pada lampiran

Dari data perhitungan rasio CAR pada tahun 2017 sampai dengan tahun 2018 mengalami kenaikan. Hal ini menunjukkan bahwa kemampuan BPR Lestari dalam menyediakan dana untuk keperluan pengembangan usaha dan menampung kemungkinan risiko kerugian yang diakibatkan dalam operasional Bank semakin meningkat. Nilai CAR tersebut menunjukan bahwa BPR Lestari berada dalam kondisi sehat. 


\section{2) Analisis Faktor Kualitas Aktiva Produktif}

Perhitungan Rasio KAP untuk tahun 2017:

$$
\begin{aligned}
\text { Rasio KAP } & : \frac{52.500 .589}{3.001894 .373} \times 100 \% \\
& : 2 \%
\end{aligned}
$$

Perhitungan Rasio KAP untuk tahun 2018:

$$
\begin{aligned}
\text { Rasio KAP } & : \frac{36.5 .06 .405}{3.302 .752 .021} \times 100 \% \\
& : 1 \%
\end{aligned}
$$

Tabel 4.10

Perhitungan Rasio KAP

\begin{tabular}{|l|l|c|c|}
\hline \multirow{2}{*}{ No } & \multirow{2}{*}{ Uraian } & \multicolumn{2}{|c|}{ Tahun } \\
\cline { 3 - 4 } & & $\mathbf{2 0 1 7}(\boldsymbol{\%})$ & $\mathbf{2 0 1 8 ( \% )}$ \\
\hline 1 & KAP & 2 & 1 \\
\hline 2 & Kriteria & SEHAT & SEHAT \\
\hline
\end{tabular}

Sumber: Data diolah, perhitungan pada lampiran

Hasil perhitungan menunjukkan keadaan yang sehat, karena semakin kecil persentase maka kondisinya semakin sehat. Dapat disimpulkan bahwa jumlah aktiva produktif pada BPR Lestari mengandung potensi tidak memberikan penghasilan sangat kecil.

\section{2) Analisis Faktor Manajemen}

Untuk penilaian terhadap faktor manajemen penulis menggunakan GCG (Good Corporate Governance) ialah prinsip yang mengarahkan dan mengendalikan perusahaan agar mencapai keseimbangan antara kekuatan serta kewenangan perusahaan dalam memberikan pertanggungjawabannya kepada para shareholders khususnya, dan stakeholders pada umumnya.

BPR Lestari sudah menerapkan prinsip GCG tersebut dengan:

a. Mengatur pola hubungan harmonis tentang peran dewan komisaris, Direksi, Pemegang Saham dan Para Stakeholder lainnya. 
b. Melakukann pengecekan dan perimbangan kewenangan atas pengendalian perusahaan yang dapat membatasi munculnya pengelolaan yang salah dan penyalahgunaan aset perusahaan.

c. Menentukan tujuan dan pencapaian perusahaan, dengan proses yang transparan.

\section{3) Analisis Faktor Rentabilitas}

a. Perhitungan Rasio ROA

Tahun 2017

$\begin{array}{ll}\text { Laba/rugi sebelum pajak } & : 186.465 .084 \\ \text { Total Aktiva } & : 3.946 .642 .927 \\ \text { Rasio ROA } & : \frac{186.465 .084}{3.946 .642 .927 \times 12 / 3} \times 100 \% \\ & : 4,72 \%\end{array}$

Tahun 2018

$$
\begin{aligned}
& \text { Laba/rugi sebelum pajak } \quad \text { : 207.664.828 } \\
& \text { Total Aktiva } \quad: 4.570 .966 .485 \\
& \text { Rasio ROA } \quad: \frac{207.664 .828}{4.570 .966 .485 \times 12 / 3} \times 100 \% \\
& \text {; } 4,54 \%
\end{aligned}
$$

Tabel 4.11

Perhitungan Rasio ROA

\begin{tabular}{|l|l|c|c|}
\hline \multirow{2}{*}{ No } & \multirow{2}{*}{ Uraian } & \multicolumn{2}{c|}{ Tahun } \\
\cline { 3 - 4 } & & $\mathbf{2 0 1 7}(\boldsymbol{\%})$ & $\mathbf{2 0 1 8 ( \% )}$ \\
\hline 1 & ROA & 4,72 & 4,54 \\
\hline 2 & Kriteria & SEHAT & SEHAT \\
\hline
\end{tabular}

Sumber: Data diolah, perhitungan pada lampiran

Berdasarkan perhitungan pada tabel 4.12 diperoleh hasil untuk rasio ROA pada tahun 2017 sebesar 4,72\% dan pada tahun 2018 sebesar 4,54\%. Walaupun terjadi penurunan sebesar $0,18 \%$, BPR Lestari berada dalam kondisi sehat karena nilai ROA masih di atas kriteria. 
b. Perhitungan Rasio BOPO

Tahun 2017

$$
\begin{array}{ll}
\text { Beban Operasional } & : 106.823 .064 \\
\text { Pendapatan Operasional } & : 151.341 .517 \\
\text { Rasio BOPO } & : \frac{106.823 .064}{151.341 .517} \times 100 \% \\
& : 70,58 \%
\end{array}
$$

Tahun 2018

$$
\begin{array}{ll}
\text { Beban Operasional } & : 109.752 .277 \\
\text { Pendapatan Operasional } & : 159.043 .833 \\
\text { Rasio BOPO } & : \frac{\mathbf{1 0 9 . 7 5 2 . 2 7 7}}{\mathbf{1 5 9 . 0 4 3 . 8 3 3}} \times 100 \% \\
& : 69 \%
\end{array}
$$

Tabel 4.12

\section{Perhitungan Rasio BOPO}

\begin{tabular}{|l|l|c|c|}
\hline \multirow{2}{*}{ No } & \multirow{2}{*}{ Uraian } & \multicolumn{2}{c|}{ Tahun } \\
\cline { 3 - 4 } & & $\mathbf{2 0 1 7}(\boldsymbol{\%})$ & $\mathbf{2 0 1 8 ( \% )}$ \\
\hline 1 & BOPO & 70,58 & 69,01 \\
\hline 2 & Kriteria & CUKUP SEHAT & CUKUP SEHAT \\
\hline
\end{tabular}

Sumber: Data diolah, perhitungan pada lampiran

Rasio biaya operasional terhadap pendapatan operasional pada tabel 4.13 menunjukkan tingkat efisiensi suatu Bank dalam operasionalnya yang mempengaruhi terhadap pendapatannya. Dari hasil perhitungan di atas diperoleh angka rasio BOPO pada tahun 2017 sebesar 70,58\% dengan kriteria cukup sehat, namun pada tahun 2018 mengalami penurunan sebesar 1,57\% menjadi 69,01\% dengan kriteria yang masih berada dalam kategori cukup sehat.

\section{4) Analisis Faktor Likuiditas}

a) Rasio aktiva lancar terhadap hutang lancar (cash ratio)

cash ratio tahun $2017 \quad: \frac{109.290 .309}{2,995.717 .760} \times 100 \%$ 


$$
\begin{aligned}
& : 3,65 \% \\
\text { cash ratio tahun } 2018 \quad: \frac{392.470 .859}{3.299 .335 .254} & \times 100 \% \\
& : 11,90 \%
\end{aligned}
$$

Tabel 4.13

Perhitungan Rasio CR

\begin{tabular}{|l|l|c|c|}
\hline \multirow{2}{*}{ No } & \multirow{2}{*}{ Uraian } & \multicolumn{2}{c|}{ Tahun } \\
\cline { 3 - 4 } & & $\mathbf{2 0 1 7}(\boldsymbol{\%})$ & $\mathbf{2 0 1 8 ( \% )}$ \\
\hline 1 & CR & 3,65 & 11,90 \\
\hline 2 & Kriteria & CUKUP SEHAT & SEHAT \\
\hline
\end{tabular}

Sumber: Data diolah, perhitungan pada lampiran

Tabel 4.14 menunjukkan bahwa cash ratio pada tahun 2017 adalah sebesar 3,65\% dan terjadi peningkatan tahun 2018 menjadi 11,90\% yang artinya bahwa BPR Lestari berada dalam kondisi cukup sehat menjadi sehat. Semakin tinggi rasio ini maka semakin baik posisi aktiva lancar untuk memenuhi kewajiban jangka pendeknya yang harus segera dipenuhi.

b) Perhitungan Rasio LDR

$$
\begin{aligned}
\text { Rasio LDR } 2017 & : \frac{2.329 .047 .334}{3.316 .077 .992} \times 100 \% \\
& : 70,23 \% \\
\text { Rasio LDR } 2018 & : \frac{2.576 .299 .340}{3.674 .192 .305} \times 100 \% \\
& : 70,12 \%
\end{aligned}
$$

Tabel 4.14

\section{Perhitungan Rasio LDR}

\begin{tabular}{|l|l|c|c|}
\hline \multirow{2}{*}{ No } & \multirow{2}{*}{ Uraian } & \multicolumn{2}{|c|}{ Tahun } \\
\cline { 3 - 4 } & & $\mathbf{2 0 1 7}(\boldsymbol{\%})$ & $\mathbf{2 0 1 8 ( \% )}$ \\
\hline 1 & LDR & 70,23 & 70,12 \\
\hline
\end{tabular}




\begin{tabular}{|l|l|c|c|}
\hline 2 & Kriteria & SEHAT & SEHAT \\
\hline
\end{tabular}

Sumber: Data diolah, perhitungan pada lampiran

Dari hasil perhitungan pada tabel 4.15 di atas, pada tahun 2017 nilai rasio LDR sebesar 70,23\% dan pada tahun 2018 sebesar 70,12\%. Adanya penurunan rasio ini menunjukkan bahwa pada setiap tahun terjadi kenaikan jumlah kredit yang diberikan pada BPR Lestari, karena semakin menurun hasil persentase rasio LDR maka semakin sehat. Rasio ini menunjukan seimbangnya jumlah kredit yang diberikan BPR Lestari seimbang dengan dana yang diterima oleh bank. Sehingga dapat disimpulkan bahwa kondisi BPR Lestarti dikategorikan sehat dilihat dari rasio kredit yang diberikan terhadap dana yang diterima.

\section{E. KESIMPULAN}

Analisis Tingkat Kesehatan Bank Berdasarkan CAMEL:

1. Faktor permodalan (CAR) pada BPR Lestari tahun 2017 sebesar 14,30\% sedangkan pada tahun 2018 sebesar $14,38 \%$. Rasio ini termasuk dalam kategori sehat yaitu dengan rasio CAR lebih dari $8 \%$.

2. Faktor kualitas aktiva produktif (KAP) pada BPR Lestari tahun 2017 sebesar 2\% sedangkan pada tahun 2018 sebesar 1\%. Walaupun mengalami penurunan, pergerakan rasio KAP tersebut menunjukkan keadaan yang sehat.

3. Faktor rentabilitas menggunakan dua rasio yaitu ROA dan BOPO. ROA pada tahun 2017 dan 2018 masing-masing sebesar 4,72\% dan 4,54\% menunjukkan berada pada kategori sehat walaupun mengalami penurunan. Sedangkan BOPO pada tahun 2017 dan 2018 masing masing $70,58 \%$ dan $69,01 \%$ mengalami penurunan juga, namun tetap dengan kriteria yang masih berada dalam kategori cukup sehat.

4. Faktor likuiditas terdiri dari dua rasio yaitu cash ratio dan LDR. Cash ratio pada tahun 2017 dan 2018 masing-masing 3,65\% dan 11,90\% berada dalam kondisi cukup sehat di tahun 2017 dan meningkat menjadi sehat pada tahun 2018. Sedangkan untuk rasio LDR termasuk dalam kategori sehat, ditunjukkan dengan hasil rasio masing masing 70,23\% dan 70,12\% untuk tahun 2017 dan 2018.

\section{F. SARAN}

Berdasarkan hasil pembahasan dan kesimpulan sebelumnya, BPR Lestari diharapkan lebih baik dan lebih mendapatkan kepercayaan yang tinggi dari masyarakat sebagai calon nasabah untuk kedepannya. Sehingga dalam pelaksanaannya, BPR Lestari perlu memperhatikan beberapa hal yang penting dalam menjaga kesehatan dan kinerja perbankkan. Hal-hal tersebut antara lain:

1. Tetap mempertahankan kualitas aktiva produktif sehingga tidak memberikan penghasilan yang sangat kecil. 
2. Memperhatikan pengeluaran biaya operasional agar dapat diimbangi dengan peningkatan pendapatan operasional, sehingga dapat menunjang pencapaian rasio efisiensi usaha yang lebih baik dari tahun

3. BPR Lestari harus lebih ketat untuk pemberian kredit, dalam artian bahwa kredit hanya diberikan pada nasabah yang benar-benar memegang teguh janjinya untuk melakukan kewajiban membayar kembali dana serta bunganya.

4. Bagi peneliti selanjutnya dapat melakukan penelitian lebih lanjut mengenai pengaruh rasio CAMEL terhadap kesehatan bank pada BPR Lestari. Selain itu dapat dicari juga faktor mana saja yang mempengaruhi tingkat kesehatan bank pada BPR Lestari dan seberapa besar pengaruhnya.

\section{DAFTAR PUSTAKA}

Anonim. 2018. Sejarah dan Gambaran Umum Perusahaan BPR Lestari.

Bank Indonesia. 1997. Surat Edaran BI No. 30/3/UPPB Tanggal 30 April 1997 Tentang Tata Cara Penilaian Tingkat Kesehatan Bank Perkreditan Rakyat. Jakarta: Bank Indonesia.

Bank Indonesia. 1997. Surat Keputusan Direktur Bank Indonesia No. 30/12.KEP/DIR/1997 tentang Tata Cara Penilaian Tingkat Kesehatan Bank Umum. Jakarta: Bank Indonesia.

Harmono. 2017. Manajemen Keuangan Berbasis Balanced Scorecard. Edisi pertama. Cetakan 6. Jakarta: Penerbit Bumi Aksara.

I Made Sudana. 2015. Manajemen Keuangan Perusahaan. Edisi kedua. Jakarta: Penerbit Erlangga.

Kasmir. 2014. Dasar Dasar Perbankan. Edisi Revisi. Jakarta: Penerbit Rajawali Pers.

Sofyan Syafri Harahap. 2015. Analisis Kritis Laporan Keuangan. Edisi pertama. cetakan 12. Jakarta: Penerbit RajaGrafindo Persada.

T. Hani Handoko. 2018. Manajemen. Edisi kedua. Cetakan 30. Yogyakarta: BPFE.

Desy Natalia. 2013. Analisis Tingkat Kesehatan Bank Berdasarkan CAMEL pada PD. BPR Bank Pasar Kulon Progo Periode 2011-2012

Undang-Undang Nomor 7 Tahun 1992 Tentang Perbankan.

Undang-Undang Nomor 10 Tahun 1998 tanggal 10 November 1998 tentang Perbankan. 